\title{
ENSINO-APRENDIZAGEM COM TECNOLOGIAS DIGITAIS NA FORMAÇÃO INICIAL DE PROFESSORES DE INGLÊS
}

\author{
TEACHING-LEARNING AND DIGITAL TECHNOLOGIES IN \\ PRE-SERVICE ENGLISH LANGUAGE TEACHER EDUCATION
}

\section{Marcus de Souza Araújo}

\section{RESUMO}

Este artigo tem por objetivo investigar a percepção de dois alunos do Curso de LetrasInglês sobre a aprendizagem e a prática pedagógica de alunos da Educação Básica com o uso das tecnologias a partir de uma disciplina curricular acadêmica. Essa investigação tem como suporte teorias que discutem o uso das tecnologias digitais da informação e comunicação no ensino-aprendizagem (BUCKINGHAN, 2010; ALMEIDA;VALENTE, 2011, 2016; BRAGA, 2013; entre outros). Com relação à metodologia, a pesquisa qualitativa se caracteriza como um estudo de caso (STAKE, 1995; YIN, 2015). Os resultados nos mostram que uma disciplina acadêmica específica sobre tecnologias tem papel relevante no curso de formação inicial de professores de inglês, pois, além de mostrar a diversidade de aprendizagem com diferentes interfaces tecnológicas digitais, possibilita, também, que o futuro professor venha a refletir sobre as potencialidades e a apropriação dessas tecnologias para fins pedagógicos.

Palavras-chave: Tecnologias Digitais da Informação e Comunicação; Curso de LetrasInglês; ensino-aprendizagem.

\section{ABSTRACT}

This article aimed at investigating two students'perceptions of an English-language teaching undergraduate program about learning and pedagogical practices of students in basic education with the use of technologies in a subject which is part of the curriculum. This investigation is grounded in theories that discuss the use of Information and Communication Digital Technologies in teaching-learning (BUCKINGHAN, 2010, ALMEIDA $;$ VALENTE, 2011, 2016; BRAGA, 2013; among others). As for the methods, the research is considered a qualitative case study (STAKE, 1995; YIN, 2015). The results show that a specific academic subject on technologies plays a relevant role in Englishlanguage teaching undergraduate programs, since not only does it provide learning diversity with different digital technological interfaces. However, it also allows the teacher-to-be to reflect upon the potential and appropriation of these technologies for teaching purposes.

Keywords: Information and Communication Digital Technologies; English-language undergraduate teacher education; teaching-learning.

\footnotetext{
* Universidade Federal do Pará, Belém (PA), Brasil, marcusaraujo@interconect.com.br
} 


\section{CONSIDERAÇÕES INICIAIS}

O desenvolvimento e o uso disseminado do computador e da Internet ocasionaram, e ainda continuam a gerar, mudanças significativas na comunicação humana contemporânea, a partir das quais, independentemente do tempo e do espaço, qualquer pessoa pode conectar-se com outras pessoas. Sob esse enfoque, a comunicação deixa de ser apenas de um para um para se tornar de muitos para muitos. Entendo, nessa direção, o computador e a Internet como tecnologias multidimensionais e como interfaces digitais usadas para práticas sociais, pois estão a serviço do homem, na tentativa de tornar sua vida mais confortável, além de integrá-lo cada vez mais aos contextos social, cultural, econômico, educacional e político da Sociedade da Informação ${ }^{1}$.

Ademais, penso, no momento, no impacto das Tecnologias Digitais da Informação e Comunicação (TDIC) no sistema educacional e nas contribuições dessas tecnologias para o ensino-aprendizagem de diferentes gerações de crianças, jovens e adultos. Esse talvez seja o maior desafio dos Cursos de Letras no Brasil na atualidade, ou seja, inserir em seus projetos político-pedagógicos (PPP) disciplinas curriculares acadêmicas diretamente ligadas à formação tecnológico-digital e pedagógica do futuro professor de línguas estrangeiras. É mister ressaltar que o Comitê Gestor da Internet no Brasil (2016) aponta que as TDIC não ocupam posição central nos PPP na maioria das escolas brasileiras (e incluo também as universidades e as faculdades) ou não são mencionadas ou ocupam posição secundária entre as prioridades e estratégias pedagógicas.

Conforme destacam Veen e Vrakking (2009), Prensky (2010, 2012, 2015), Kenski (2012b, 2013), Fava $(2014,2016)$, entre outros, a geração digital não se adapta ao modelo de educação tradicional, no qual o professor fala, ministra sua aula como se fosse um palestrante, enquanto o aluno, sentado, escuta-o de maneira passiva. Os tempos mudaram e as pessoas, também. Afinal, a nova geração de crianças e de jovens deseja interagir, compartilhar, sentir-se desafiada, usar e incorporar as TDIC diariamente, frequentemente, para navegar, encontrar informação, compartilhá-la, postar vídeos e fotos em redes sociais, usar o telefone celular para se comunicar, enviar mensagem, jogar, entre outras atividades. Em outras palavras, a informação e as variedades de aplicativos estão disponíveis por meio de apenas um clique ou

1. Uma sociedade baseada e influenciada pelo computador e pela Internet (CASTELLS, 2003), como também pelas novas tecnologias digitais da informação e comunicação. Segundo Bates (2016) e Pischetola (2016), essa sociedade está centrada na cultura da busca, transmissão, exposição, compartilhamento e curtidas de informações para a interatividade e o engajamento sociais e, também, profissionais. 
de um toque na tela do celular na era digital (COMITÊ GESTOR DA INTERNET NO BRASIL, 2016; BATES, 2016; FAVA, 2016).

A Organização das Nações Unidas para a Educação, a Ciência e a Cultura (UNESCO, 2009) aponta que os cursos ou programas de formação estão deixando a desejar em relação ao desenvolvimento de competências para o uso das tecnologias da informação e comunicação dos professores no contexto educacional. Por essa razão, vejo a necessidade de incorporar ações concretas nos cursos de Letras por meio de inclusão de disciplinas acadêmicas curriculares que tratem, especificamente, do uso reflexivo, funcional e pedagógico das TDIC nos diferentes contextos de ensino-aprendizagem de línguas estrangeiras nos quais esses docentes poderão vir a atuar, seja na esfera particular, seja na esfera pública. Essas disciplinas dariam ao aluno do curso de Letras oportunidades para vivenciar situações pedagógicas teórico-práticas com as TDIC, além de oferecerem aos educandos oportunidades de questionar, argumentar e pensar nas facilidades e nos entraves que essas tecnologias para fins educacionais podem trazer para a sua formação como aprendiz e futuro professor de inglês, foco deste artigo. Assim, essa formação, em especial, proporcionaria a familiarização com essas tecnologias, tornando o futuro professor letrado digitalmente.

Nessa perspectiva, o presente artigo tem como objetivo investigar o uso das tecnologias digitais da informação e comunicação para fins educacionais na formação inicial de professores de inglês. Seu foco está na percepção de dois alunosprofessores $^{2}$ do curso de Letras-Inglês da Universidade Federal do Pará (UFPA) acerca do uso das TDIC para a aprendizagem e para a prática pedagógica de inglês, especificamente, no ensino da Educação Básica no contexto brasileiro. Sob esse enfoque, para colocar em ação essa proposta, tive como meta responder à pergunta que orienta este artigo: Como o uso das TDIC se faz presente na aprendizagem dos alunos da Educação básica e na prática pedagógica do professor na percepção de futuros professores de inglês?

Para responder a essa pergunta, tenho como proposta tecer reflexões a respeito das tecnologias no contexto educacional atual. Em seguida, apresento a metodologia que gerou os dados, os resultados e a análise dos dados. Finalizando, algumas considerações com o objetivo de retomar o que foi tratado na análise.

2. Para a análise, decidi referir-me aos participantes da pesquisa como aluno-professor, pois minha pesquisa foi realizada com alunos do curso de Letras, futuros professores de inglês. Dessa forma, ao me direcionar apenas ao aluno e ao professor, refiro-me aos alunos de minha turma ou a aluno de maneira geral e ao professor, também, de maneira geral, respectivamente. 


\section{FUNDAMENTAÇÃO TEÓRICA}

As Tecnologias Digitais da Informação e Comunicação (TDIC) trouxeram contribuições consideráveis para o mundo contemporâneo, proporcionando mudanças significativas na sociedade, economia, educação e cultura, além da maneira de os sujeitos se expressarem linguisticamente (BRAGA, 2013; BARTON, LEE, 2015). Essas tecnologias vêm influenciando, cada vez mais, o modo de ensinar e de aprender (BATES, 2016), alterando, assim, a vida de crianças, jovens e adultos.

$\mathrm{Na}$ perspectiva de Tapscott (2010), o computador, a Internet e outras tecnologias digitais configuram uma revolução ativa tanto nas gerações $Y$ como na geração Z, com propósitos sociais e interativos. Essas gerações veem as TDIC como uma extensão natural de seus cotidianos, razão pela qual são denominadas Homo zapiens, como bem definiu Veen e Wrakking (2009). Fava (2014, p. 54) complementa que "a geração $\mathrm{Y}$ foi dominada pela tecnologia, a geração $\mathrm{Z}$ é dominada pela velocidade da tecnologia." Trata-se de gerações consumistas e influentes nas suas decisões de escolha, pois "querem algo que sirva para eles - onde, quando e da maneira que quiserem. Não são consumidores passivos do modelo massivo. [...] estão ávidos para contribuir com a marca." (TAPSCOTT, 2010, p. 224).

Certamente, a Sociedade da Informação tem sido influenciada pela mudança de ser, de fazer, de agir, de pensar e de consumir dos jovens, principalmente, na visão de Prensky $(2010,2012)$, pelo aparecimento e pela rápida disseminação das TDIC. Isso me leva a retomar o enunciado do brilhante filósofo francês René Descartes, "Penso, logo existo", e construir uma analogia para as gerações $Y$ e $Z$, que são as gerações do "Faço, logo existo." Nessa direção, concordo com Prensky (2010), quando afirma que o potencial das TDIC está sacramentado, sem possibilidade de caminho de volta, tanto para as crianças e os jovens que passam a maior parte do tempo on-line, como também para os adultos, ou seja, na visão do autor, trata-se da singularidade digital. Em consonância com essa visão de Prensky (2010), Barton e Lee (2015) cunham a expressão domesticação da tecnologia, uma vez que as tecnologias (digitais) são integradas à vida das pessoas. Além disso, os usuários "se apropriam de tecnologias para facilitar suas atividades cotidianas. Isso tudo tem acontecido num período relativamente curto e se tornou rotineiro e despercebido na vida das pessoas." (BARTON, LEE, 2015, p. 12).

Segundo Prensky (2010; 2012), Kenski (2012a; 2012b) e Pérez-Gómez (2015), adquirir o computador ou qualquer outra interface digital não é suficiente para o usuário se tornar um conhecedor da tecnologia. Porém, saber usá-la de acordo com as necessidades de cada sujeito e suas especificidades torna as TDIC potentes e dinâmicas interfaces no processo educacional. 
Apesar de serem reconhecidas como essenciais na educação, as TDIC ainda são pouco exploradas e usadas em todas as suas potencialidades e suas possibilidades pelos professores de maneira pedagógica com seus alunos. Pensar nas TDIC didaticamente, de acordo com o Comitê Gestor da Internet no Brasil (2016), é saber usá-las como interfaces protagonistas, para aprimorar o ensino e os propósitos reais de aprendizagem, na tentativa de modificar e transformar a realidade da sala de aula tradicional. Além disso, essas tecnologias podem capacitar o aluno a tornar-se um usuário competente e crítico (COSCARELLI; KERSCH, 2016) e, portanto, um agente do conhecimento, como bem professa Freire (1996/2004).

Para que essas mudanças na sala de aula sejam coerentes, significativas e possam, de fato, tornar as escolas, e também as universidades, verdadeiras agências interdisciplinares para o uso consciente, funcional e pedagógico das TDIC, Braga e Vóvio (2015) ponderam que o currículo - e aqui acrescento, também, o projeto político-pedagógico da escola ou da universidade - não seja engessado e tradicional. Dessa forma, faço também minhas as palavras de Almeida et al. (2017), ao pontuarem que

a disseminação do uso das TDIC, o vertiginoso avanço da ciência e as transformações sociais fazem com que o referencial sobre currículo assuma novas características e se apresente com uma multiplicidade de referências e orientações teóricas e metodológicas. Surgem, assim, as propostas curriculares multi, inter e transdiciplinares, que permitem compreender e tratar do currículo contextualizado e multirreferencial, que se concretiza na prática social pedagógica e cultural ao incorporar os elementos do cotidiano trazidos pelas experiências de professores, professoras, alunos e alunas nas distintas redes de interação das quais participam, desenvolvem e aprendem. (ALMEIDA et al., 2017, p. 393, grifos meus).

Saliento, assim, a importância da integração da cultura digital no ambiente de sala de aula no contexto brasileiro, em que os alunos poderão se apropriar, pedagógica e conscientemente, das mídias digitais e das tecnologias (IANNONE; ALMEIDA; VALENTE, 2016; ELEÁ; DUARTE, 2016; PISCHETOLA, 2016). Em outras palavras, é trazer e integrar à sala de aula o que já está legitimado fora dela, a cultura mediada pela tecnologia e todas as suas potencialidades. Assim sendo, compartilho a visão de Buckingham (2010, p. 42) quando afirma que "se as escolas de certa forma não foram atingidas pelo advento da tecnologia digital, o mesmo não pode ser dito da vida das crianças quando estão fora da escola." Complementando a visão do autor, acrescento também os jovens e os adultos.

Buckingham (2010) enfatiza que a escola não pode ignorar a relação que as tecnologias e as mídias digitais passaram a ter na vida da maioria das pessoas e seu papel é mais que fundamental para ampliar o acesso à cultura digital, evitando, assim, um hiato entre a cultura oferecida pela escola e a cultura digital vivenciada 
fora do contexto extraescolar, tanto pelas crianças e pelos jovens, como pelos adultos, conhecida como "cultura tecnopopular" (BUCKINGHAM, 2010, p. 43). Em outras palavras, segundo esse autor, trata-se de uma tecnologia que "se tornou do domínio da cultura popular." (BUCKINGHAM, 2010, p. 39).

A nova versão da Base Nacional Comum Curricular (BNCC) para os ensinos infantil e fundamental (BRASIL, 2017) propõe dez competências, tanto cognitivas como socioemocionais, que devem ser desenvolvidas ao longo de todo o ciclo da Educação Básica. Dentre essas competências está a utilização das TDIC. De acordo com o referido documento, o aluno deve saber usá-las de maneira crítica, significativa, reflexiva e ética nas diversas práticas do cotidiano (incluindo as escolares) ao se comunicar, acessar e disseminar informações, produzir conhecimentos e resolver problemas. Entendo, assim, ser necessário o uso consciente e regular das TDIC pelos professores em suas disciplinas e contextos específicos, com currículos flexíveis que favoreçam a utilização e a integração das tecnologias para transformar a educação no contexto brasileiro, pois o uso das TDIC está cada vez mais presente, e sem volta, no dia a dia. Por esse motivo, a necessidade de cursos de formação para instrumentalizar o professor a aprender a operacionalizar, de maneira reflexiva, funcional e pedagogicamente as TDIC em suas práticas educacionais.

A partir das perspectivas de Ramos e Freire (2009), Almeida e Valente (2011), Bernabé (2012), Costa (2013) e Kenski (2013), os cursos de formação docente deveriam repensar novos caminhos, "gerando questionamentos" (RAMOS; FREIRE, 2009, p. 34) e levar em consideração não apenas o quê, o como e o quando fazer, que implicam a dimensão instrumental das TDIC, mas o porquê e o para quê, isto é, sua dimensão estratégica também deve ser considerada (COSTA, 2013). Com base nesses argumentos, parafraseio Eleá e Duarte (2016) ao professarem que as TDIC precisam ser entendidas, integradas, adaptadas e reelaboradas em cursos de formação de professores como interfaces educativas, plurais e indissociáveis do currículo e do projeto político-pedagógico da instituição, podendo ser relacionadas às ações de educar com TDIC (integração das tecnologias em práticas pedagógicas planejadas), educar para TDIC (reflexão crítica do uso funcional das tecnologias como objeto de ensino-aprendizagem) e educar por meio da TDIC (materiais didáticos realizados por meio das tecnologias).

Nesse contexto, adoto a ideia de Pischetola (2016) ao explicitar que:

a formação deve mudar a percepção da tecnologia, antes mesmo de sua utilização. Deve ser capaz de ativar reflexões pedagógicas e abrir novos horizontes culturais que incluam a predisposição à mudança das práticas pedagógicas e a reflexão sobre o ensino-aprendizagem centrado no aluno. (PISCHETOLA, 2016, p. 125). 
Assim sendo, advogo a necessidade de considerar o impacto que essas tecnologias podem exercer no processo de ensino-aprendizagem e na formação cognitiva e social do aluno, ou seja, o foco não deve estar na competência técnica da interface digital, mas em suas competências funcional e operacional, de acordo com os objetivos de aprendizagem, o contexto e a área específicos de cada professor. É relevante acentuar, assim, a reflexão para a integração pedagógica das TDIC na formação de professores (em relação a este artigo, do docente de língua inglesa), para que as inovações pedagógicas possam, de fato, acontecer na sala de aula no contexto educacional brasileiro de maneira consciente e criativa (BRITO, PURIFICAÇÃO, 2015; BATES, 2016).

Faz-se relevante mencionar que a formação inicial do professor esteja cada vez mais próxima das necessidades locais e dos contextos didático-pedagógicos de cada professor, considerando, também, as especificidades das TDIC para o ensinoaprendizagem. Como Kenski (2012a; 2012b), Moran (2012; 2013), Costa (2013), Prensky (2015) e Bates (2016) declaram, as TDIC são importantes para a educação do futuro, porém, sozinhas, não podem resolver todos os problemas decorrentes do ensino-aprendizagem.

\section{METODOLOGIA}

A presente pesquisa busca construir um conhecimento sistemático a partir de um caso em particular, em um contexto natural, e a partir da percepção e compreensão de determinados atores sociais. Assim sendo, enquadra-se em uma abordagem de pesquisa qualitativa, constituindo-se em um estudo de caso (STAKE, 1995; YIN, 2015), mais precisamente na área da Linguística Aplicada.

Como área de pesquisa indisciplinar (MOITA LOPES, 2006), a Linguística Aplicada (LA) no Brasil compreende "a linguagem como prática social" (FABRÍCIO, 2006, p.48), parte integrante da sociedade e da cultura contemporâneas, que se situa em um momento sócio-histórico e cultural. Fabrício (2006, p. 48) também pondera que as práticas discursivas na LA "não são neutras, e envolvem escolhas (intencionais ou não) ideológicas e políticas, atravessadas por relações de poder, que provocam diferentes efeitos no mundo social." Por essa razão, Celani (2016) complementa que o componente que define a LA é o ser humano em ação, em seu contexto social.

Caminhando nessa direção, os dados da pesquisa foram gerados a partir da disciplina Tecnologias no ensino/aprendizagem de línguas estrangeiras, com carga horária de 68 h/a. Essa disciplina, incluída pela primeira vez no novo PPP da Faculdade de 
Letras Estrangeiras Modernas (FALEM) da Universidade Federal do Pará (UFPA) em janeiro de 2010, tem duração de um semestre eletivo, sendo ofertada aos alunos de Letras-Inglês sempre no segundo semestre de cada ano letivo, período em que os dados foram gerados. As aulas aconteciam duas vezes por semana no turno noturno das $18 \mathrm{~h} 30 \mathrm{~min}$ às $20 \mathrm{~h} 10 \mathrm{~min}$. É mister ressaltar que o curso de Letras-Inglês apresenta duas entradas anuais: um grupo de alunos no primeiro semestre letivo para o turno noturno, e o outro grupo de alunos no segundo semestre, para o turno matutino. Em média, há cerca de 30 ingressantes no curso por semestre em cada turno.

Em relação aos participantes da pesquisa, quatro alunos se voluntariaram para a geração dos dados. Esses alunos faziam parte de um grupo maior de dezoito alunos, que cursaram a disciplina curricular Tecnologias no ensino/aprendizagem de linguas estrangeiras, no semestre em que foram gerados os dados para esta pesquisa. Não obstante, por razões de espaço neste artigo, apresento a seleção dos excertos das falas de apenas dois alunos, cujos nomes fictícios são Lasn e Ralph.

A participante Lasn tinha 27 anos quando a pesquisa foi realizada e havia cursado toda a Educação Básica em escola pública. Concluiu o Ensino Médio em 2002. Fez um curso preparatório para realizar as provas do vestibular durante um ano e seis meses para ingressar na UFPA, em 2011. No momento da geração dos dados, lecionava inglês em uma escola particular em Belém, para as quarta e quinta séries do Ensino Fundamental I, há um ano e meio. Em relação às expectativas para com a disciplina curricular, esperava associar o uso dos recursos tecnológicos ao ensino de inglês de maneira eficiente e prática.

Já Ralph tinha 23 anos e havia cursado o Ensino Fundamental em escola pública e o Ensino Médio em escola particular, concluindo-o em 2006. Ingressou na UFPA em 2011. Na época da coleta dos dados, trabalhava nos cursos de idiomas dessa universidade, conhecidos como Cursos Livres de Línguas Estrangeiras (CLLE), desde o segundo semestre de 2012, com turmas de inglês de níveis básicos e intermediários, que correspondem aos níveis 1 a 7 do curso. A expectativa inicial de Ralph em relação à disciplina era lidar com os fatores positivos e os negativos que as tecnologias digitais podem oferecer, além de saber administrá-los e empregálos de maneira criativa e eficiente.

Em relação aos instrumentos da pesquisa, foram utilizados dois questionários (aplicados no início e no final da disciplina), entrevista, relatos reflexivos dos alunos ao longo de todo o semestre letivo e notas de campo do pesquisador.

O questionário inicial teve como objetivo obter informações sobre o perfil pessoal e acadêmico dos participantes e o questionário final teve como objetivo 
obter informações sobre o grau de dificuldade e as preferências dos participantes em relação às TDIC estudadas ao longo do semestre. Por sua vez, a entrevista foi gravada em áudio em uma sala de aula da própria FALEM e teve como objetivo elucidar as respostas fornecidas pelos participantes nos questionários e nos relatos reflexivos. Já os relatos reflexivos eram escritos pelos participantes com o objetivo de refletir a respeito das interfaces tecnológicas digitais que aprendiam em sala de aula, mostrando suas facilidades e suas dificuldades. Finalmente, as notas de campo foram utilizadas pelo pesquisador para descrever as reflexões e as observações sobre os procedimentos de sua sala de aula.

\section{ANÁLISE DOS DADOS}

Esta seção corresponde ao percurso de cada um dos dois participantes, Lasn e Ralph, alunos do Curso de Letras-Inglês, relacionado à aprendizagem e à prática pedagógica dos alunos da Educação Básica no contexto brasileiro com o uso das TDIC, de acordo com suas respectivas percepções. Assim sendo, trago à tona seus excertos de fala e suas inferências que contribuíram para responder à pergunta da pesquisa: Como o uso das TDIC se faz presente na aprendizagem dos alunos da Educação Básica e na prática pedagógica do professor na percepção de futuros professores de inglês?

\subsection{0 percurso de LASN}

A presente seção apresenta a visão de Lasn em relação à aprendizagem e à prática pedagógica dos alunos da Educação Básica com o uso das TDIC.

\subsubsection{Aprendizagem dos alunos da Educação Básica com o uso das TDIC}

Lasn acredita que parte dos alunos das escolas brasileiras parecem já possuir uma familiarização com o uso das TDIC por fazerem parte de uma geração de crianças e de jovens nascidos em um ambiente digital, além de serem usuários frequentes. Segundo ela, o uso cotidiano das TDIC leva essa geração de alunos a conhecerem suas funcionalidades e dominá-las com certa propriedade, como pode ser observado no excerto a seguir:

Transcrição 1: entrevista

Marcus: Esclarece para mim a sua fala no questionário inicial, quando você diz: "a facilidade que se dá pelo fato dos alunos terem amplo conhecimento sobre o assunto [uso da tecnologia]". 
Lasn: [...] o fato das crianças e dos jovens ${ }^{3}$ nascerem em uma era digital, em uma era em que usam a tecnologia de diversas formas, para jogar, bater papo no Face(book), baixar e ouvir música, postar fotos, né? estão mais inseridos nesse meio. Trabalhar com algo que eles conhecem no dia a dia é uma forma de facilitar o ensino de inglês, na minha opinião.

Marcus: Isso ajuda?

Lasn: Sim, porque as crianças e os jovens já conhecem a tecnologia, eles já têm um certo domínio, ainda que eles não conheçam essa tecnologia para aprender, para a questão pedagógica, mas eles já conhecem como funciona porque são usuários frequentes no dia a dia, então isso já facilita muito. [...] trabalhar com algo que eles já conhecem é muito melhor, pode tornar a aprendizagem de inglês mais interessante e desafiadora para eles [alunos].

$\mathrm{O}$ argumento da aluna-professora aponta para uma geração de alunos, de crianças e de jovens, que já nasceu inserida na tecnologia digital, o que pode facilitar, segundo ela, o ensino-aprendizagem da língua inglesa. $\mathrm{O}$ ponto de vista de Lasn corrobora as ideias de Veen e Vrakking (2009) e Tapscott (2010) ao afirmarem que a geração de crianças e de jovens da atualidade, a geração $Z$, domina as tecnologias digitais, porque nasceu em um mundo tecnológico. Essa geração está mais exposta, constantemente, às interfaces tecnológicas digitais, o que ajuda a conhecer suas funcionalidades e suas operacionalizações.

Pode-se verificar, ainda, no excerto final da entrevista, que a aluna-professora deixa transparecer a interligação das tecnologias com o aluno como algo natural, por serem usuários que estão diariamente cada vez mais conectados. Ademais, Lasn enumera também algumas atividades que os alunos realizam nesse meio digital, como jogar games, conversar pelo Facebook, baixar aplicativos de música para ouvi-la e publicar fotos. Por essa razão, torna-se interessante e desafiador trabalhar com algo com que os alunos já estão familiarizados, segundo a visão da aluna-professora.

As considerações de Lasn estão em consonância com o pensamento de Prensky $(2010,2012)$, ao salientar que a tecnologia pode se constituir uma aliada favorável para o aluno na esfera educacional pelo fato de conhecer e de dominar sua função e sua instrumentalização para o entretenimento, por estar cada vez mais presente em seu cotidiano. Para esse autor, trazer as tecnologias para o contexto escolar do aluno é permitir sua inclusão digital e torná-lo um cidadão participativo e reflexivo no mundo contemporâneo. A visão de Lasn mostra uma conscientização para o nicho das TDIC no ensino-aprendizagem de inglês do aluno da Educação

3. Decidi destacar em negrito alguns excertos dos alunos-professores com o objetivo de ressaltar informações relevantes, para que possam me ajudar a analisar os resultados desta pesquisa. 
Básica, visto que a aluna-professora ressalta a importância da familiarização que o aluno já possui com essas tecnologias como uma parceria viável e concreta.

Lasn complementa seu pensamento sobre a dinamicidade, a agilidade e a flexibilidade das TDIC nos tempos atuais:

\section{Transcrição 2: questionário final}

Lasn: Os recursos tecnológicos são dinâmicos, ágeis e flexíveis, ou seja, estão de acordo com a atual geração de crianças e jovens que pensa diferente dos adultos e realiza diversas atividades ao mesmo tempo, ouvir música, assistir a TV e conversar com as pessoas no Face(book), entre outras.

A fala da aluna-professora está em consonância com as ideias de Cecchettini (2011) e Fava $(2014$, 2016) ao afirmarem que a geração Z é multitarefada, consegue realizar duas, três ou mais atividades ao mesmo tempo, sem perder a concentração. Assim, a fala de Lasn leva-me a deduzir que as TDIC podem ajudar o aluno a realizar atividades pedagógicas diversas de inglês nesse novo contexto da educação da era digital, modificando e alterando sua aprendizagem, para que se possa manter seu interesse e sua motivação na escola. Considera-se, também, que as crianças e os jovens pertencem a uma geração dinâmica, ágil e flexível, como as TDIC.

A partir da fala de Lasn, pode-se observar que o uso das TDIC pode facilitar a aprendizagem, uma vez que, para a participante, o aluno:

- nasceu em uma era digital;

- usa as TDIC com certa familiaridade em atividades de entretenimento;

- possui um certo domínio das TDIC;

- conhece como as TDIC funcionam e

- realiza diversas atividades ao mesmo tempo por meio das TDIC.

\subsubsection{Prática pedagógica do professor com o uso das TDIC}

Lasn demonstra conscientização acerca do papel do professor para o uso das TDIC no contexto educacional contemporâneo, que comunga com as necessidades da geração atual de alunos. Conforme afirmado antes neste artigo, as tecnologias estão a serviço do homem para tornar suas atividades e práticas acessíveis em seus cotidianos. $\mathrm{O}$ excerto abaixo apresenta essa observação: 
Transcrição 3: questionário final

Lasn: Cabe ao professor rever e atualizar as suas estratégias de ensino e de aprendizagem para melhor atender a atual geração de alunos, cada um com seus interesses e suas necessidades próprios. Hoje, vejo as crianças e os jovens cada vez mais independentes, mais ativos, pois a tecnologia possibilita isso. Por isso, acho que o professor não é o único que sabe mais nessa nova era. As tecnologias aproximam cada vez mais o professor e o aluno, o que torna o professor um (co)orientador, que precisa trabalhar em parceria com seus alunos.

Pode-se observar a preocupação da aluna-professora em relação ao papel do professor em melhor atender aos interesses e às necessidades dos alunos, percebendo as TDIC como uma interface mediadora entre o fazer do professor e o aprender do aluno em sala de aula. $\mathrm{O}$ professor, atualmente, encontra-se em uma posição de aprendiz na era digital e não como um sujeito que domina o conhecimento completamente, razão pela qual a educação bancária (FREIRE 1968/2014) se torna menos aceitável nessa nova era. Com as mudanças ocasionadas pelas tecnologias, o professor terá de modificar a sua forma de ensinar, pois o aluno modificou a sua maneira de aprender, o que me leva a concordar com Masetto (2013, p. 143), ao pontuar que "nem todos aprendem do mesmo modo, no mesmo ritmo e ao mesmo tempo". Nesse sentido, o ensino mediado pelo uso das TDIC pode respeitar os diferentes ritmos de aprendizagem de cada aluno.

Lasn ainda menciona em seu relato reflexivo algumas considerações encontradas nas interfaces digitais para a prática pedagógica do professor ao fazer referência ao seminário apresentado por ela e por seus colegas de equipe e de turma, em sala de aula, a respeito do uso de várias dessas interfaces selecionadas pelos alunos-professores e pelo professor-pesquisador. $\mathrm{O}$ excerto a seguir pode ilustrar essa ponderação:

\section{Transcrição 4: relato reflexivo}

Lasn: Todas as ferramentas apresentadas tinham um público-alvo, um objetivo específico. Então, dependendo de meu objetivo, uma ferramenta é mais apropriada que outra. Todas têm algo de positivo, vai depender do meu objetivo, o que quero ensinar e de que maneira. Assim, entra a questão de saber adaptar. Se vou ensinar inglês em uma turma, por exemplo, do sexto ano, eu não vou pedir uma certa atividade que esteja além da capacidade das crianças, porque elas vão ficar confusas e aquilo vai ficar cansativo, e vou explicar várias vezes. Logo, esse fator pode levar a atividade a não ser bem sucedida. 
Observa-se a preocupação da aluna-professora em adaptar a atividade com a interface digital escolhida para um determinado propósito de ensino-aprendizagem para um determinado grupo de alunos. A interface em si, escolhida para qualquer objetivo, não oportunizará eficiência e sucesso para a aula do professor. Por essa razão, o excerto número quatro leva-me a deduzir a importância de um olhar reflexivo para a prática do professor como forma de tomar decisões sobre sua ação e suas escolhas a serem feitas (RAMOS; FREIRE, 2009; CELANI, 2010b; LIBERALI, 2010; RAMOS, 2010, entre outros) para o uso consciente das TDIC em seu próprio contexto de ensino-aprendizagem.

Essa análise mostra que, para Lasn, a prática pedagógica do professor para o uso das TDIC deve:

- rever e atualizar estratégias de ensino e de aprendizagem;

- atender a atual geração de alunos;

- identificar o público-alvo e o(s) objetivo(s);

- saber adaptar a um determinado contexto de ensino e de aprendizagem;

- tornar essa prática interligada com o aprender do aluno e

- trabalhar em parceria com o aluno.

Por meio da análise dos dados, pode-se observar que Lasn parece ter consciência das contribuições oferecidas pelo uso das tecnologias digitais da comunicação e informação para a aprendizagem do aluno e para a prática pedagógica do professor. Em relação às contribuições das TIDC para a aprendizagem do aluno da Educação Básica no contexto brasileiro, Lasn acredita que os alunos nascidos em uma época digital conhecem e sabem usar as interfaces em seu cotidiano para realizar diversas atividades. Esse conhecimento pode possibilitar, assim, uma ação pedagógica eficaz, sistematizada, para o ensino-aprendizagem de inglês.

A aluna-professora reconhece também que os alunos atualmente pensam e agem diferentemente dos adultos, por estarem inseridos em um mundo em que as TDIC estão cada vez mais presentes, como mostra o excerto de número dois, pois as interfaces digitais, segundo ela, são dinâmicas, ágeis e flexíveis.

Lasn parece apontar para um contexto atual totalmente mutável, razão pela qual o aluno, inserido nesse novo contexto, também mudou. Assim como as tecnologias, o aluno também é dinâmico, realiza várias ações ao mesmo tempo, conecta-se e procura o que deseja com rapidez; é flexível, adapta-se ao mundo e às inovações tecnológicas com facilidade. Para Lasn, as TDIC podem viabilizar o ensino-aprendizagem de inglês do aluno, ou seja, trazer para o ambiente de sala de aula o que é familiar fora dele. Nessa perspectiva, compreendo a importância 
de trazer e de integrar à sala de aula o que já está legitimado fora dela, a cultura mediada pela tecnologia e todas as suas potencialidades. Assim sendo, compartilho a visão de Buckingham (2010, p. 42), quando afirma que "se as escolas de certa forma não foram atingidas pelo advento da tecnologia digital, o mesmo não pode ser dito da vida das crianças quando estão fora da escola". Complementando a visão do autor, acrescento também os jovens e os adultos nesse contexto.

No que diz respeito às contribuições das TDIC para a prática pedagógica do professor, Lasn acredita que as TDIC podem facilitar seu trabalho, pois, com seus usos funcionais, o professor pode rever e atualizar estratégias de ensino e de aprendizagem para melhor adaptá-las às tendências atuais, além de atender a geração atual de alunos, como mostra o excerto número três. A percepção de Lasn com relação às contribuições de uso das TDIC, tanto para a aprendizagem dos alunos na Educação Básica como para a prática pedagógica do professor, fazem-me inferir que é possível aprender e ensinar inglês por meio dessas tecnologias. No entanto, entendo que é preciso que o professor possa fazer as adaptações necessárias à sua prática, para atender às necessidades e às expectativas de seus alunos. Diante disso, não há como negar a importância da inserção das tecnologias no contexto educacional brasileiro da contemporaneidade.

\subsection{0 percurso de RALPH}

Nesta seção, apresento a visão de Ralph em relação à aprendizagem dos alunos da Educação Básica e à prática pedagógica do professor com o uso das TDIC.

\subsubsection{Aprendizagem dos alunos da Educação Básica com o uso das TDIC}

Ralph acredita que as tecnologias podem facilitar a aprendizagem de inglês por promoverem a interatividade:

\section{Transcrição 5: questionário inicial}

Ralph: As TDIC trazem interatividade, modernidade e imersão do aluno no mundo, que está em constante mudança. Isso pode facilitar para ele aprender inglês na escola. $\mathrm{O}$ aluno quer novidade e as tecnologias estão sempre em evolução.

A fala de Ralph remete para a facilidade que as TDIC podem trazer para a aprendizagem de inglês em sala de aula, tanto pelo aspecto da interatividade como da modernidade. $\mathrm{O}$ aluno-professor pode dar ênfase a esses dois aspectos em função de ser usuário frequente de aparelhos tecnológicos e por estar conectado 
permanentemente. Como as tecnologias correspondem a interfaces digitais recentes, esse aspecto moderno, possivelmente, alarga o elo de interesse dos alunos para se comunicarem e navegarem pela rede cada vez mais, entre outras atividades.

Nessa direção, inserir o aluno na educação digital, do ponto de vista de Ralph, pode trazer facilidades e novidades para a aprendizagem da língua alvo. Sou favorável, parcialmente, à opinião de Ralph, pois as TDIC, em si mesmas, não são garantias de facilidade e de novidade no processo de ensino-aprendizagem, ou seja, não transformam a prática pedagógica do professor com a sua simples inclusão no contexto escolar (e acadêmico), também incluo o PPP e o currículo. Compreendo que a mudança possivelmente aconteça quando o professor criticamente se familiariza com as TDIC como um componente pedagógico e curricular, o que leva, a meu ver, a dialogar com seus alunos por meio das tecnologias, tornando o ensino democrático e inclusivo. Como salientam Palfrey e Gasser (2011), o mundo digital oferece novas oportunidades para quem sabe como aproveitá-las, possibilitando novas formas de criatividade, aprendizagem, empreendimento e inovação.

Ralph ainda declara a relevância das tecnologias para os alunos como uma maneira de sair do tradicional:

\section{Transcrição 6: questionário final}

Ralph: É importante ressaltar que a tecnologia é uma peça fundamental no dia a dia dos alunos atuais, o que pode provocar neles uma identificação e maior interesse para aprender inglês na escola. É uma forma de sair de métodos antiquados, tradicionais como o simples uso do quadro e do giz.

Ralph salienta, assim como Lasn, a importância e a necessidade de integração das tecnologias presentes no cotidiano dos alunos ao contexto de sala de aula para a aprendizagem de inglês. Assim, temos o que Barton e Lee (2015, p. 12) chamaram de "domesticação da tecnologia", contexto no qual as TDIC são integradas à vida das pessoas.

Nessa direção, concordo com Buckingham (2010), ao enfatizar que a escola não pode ignorar a relação que as tecnologias e as mídias digitais passaram a ter na vida da maioria das pessoas. Para o autor, seu papel é mais do que fundamental para ampliar o acesso à cultura digital, evitando, assim, um hiato entre a cultura oferecida pela escola e a vivenciada fora do contexto escolar tanto pelas crianças e pelos jovens como pelos adultos, conhecida como cultura tecnopopular (BUCKINGHAM, 2010, p. 43). Em outras palavras, trata-se de uma tecnologia que "se tornou do domínio da cultura popular" (p. 39). Por essa razão, concordo mais uma vez com Barton e Lee $(2015$, p. 12), quando afirmam que os usuários "se 
apropriam de tecnologias para facilitar suas atividades cotidianas. Isso tudo tem acontecido num período relativamente curto e se tornou rotineiro e despercebido na vida das pessoas".

As argumentações de Ralph mostram que ele acredita que a aprendizagem dos alunos com o uso das TDIC:

- traz interatividade, atualização e imersão dos alunos no mundo atual ${ }_{i}$

- facilita a aquisição da língua-alvo;

- traz novidade para o ensino-aprendizagem e

- proporciona formas para deixar de utilizar métodos tradicionais.

\subsubsection{A prática pedagógica do professor com o uso das TDIC}

Ralph manifesta sua opinião, apontando a necessidade da formação constante do professor para melhorar a sua prática com o uso das tecnologias. É importante salientar a integração das tecnologias à formação do professor de inglês. Ralph argumenta:

\section{Transcrição 7: entrevista}

Marcus: Quais facilidades você aponta para o uso das tecnologias para o professor? Ralph: Como falei elas trazem uma modernidade para o ensino.

Marcus: Pode ficar melhor?

Ralph: Eu acho que fica... o aluno fica mais interessado, gosta de aprender.

Marcus: E o professor?

Ralph: O que tem o professor?

Marcus: $\mathrm{O}$ professor está preparado para essa mudança?

Ralph: O professor precisa se reclicar porque senão ele fica para trás. O professor precisa deixar de ser tradicional.

Marcus: Como assim tradicional?

Ralph: Usa muito o livro [didático] e o quadro [...] precisa inovar [...] e as tecnologias são uma mão na roda. Na minha opinião, o professor precisa saber usar as tecnologias, ajudam na sua prática, melhora o ensino, estimula o aluno para aprender inglês, ver o que o aluno quer, né? Acho importante se reciclar, fazer um curso ou uma disciplina como essa para ficar mais confiante para ensinar inglês com a ajuda das tecnologias, claro, [...] acho que é isso!

Ralph não responde de imediato à pergunta proposta no início da entrevista, mas ficam evidentes seu interesse e as facilidades que o uso da tecnologia traz para a prática do professor para fins educacionais. No segundo momento, ao ser indagado 
sobre os benefícios que poderiam ser trazidos pelas TDIC para o professor, deixa transparecer a necessidade de formação do professor. Essa necessidade fica evidente nas ideias de Pischetola (2016, p. 125), ao pontuar que "a formação deve mudar a percepção da tecnologia, antes mesmo de sua utilização. Deve ser capaz de ativar reflexões pedagógicas e abrir novos horizontes culturais que incluam a predisposição à mudança das práticas pedagógicas [...]".

Isso posto, caso o professor tenha uma formação adequada, poderá tornar-se confiante para usar as tecnologias no ensino de inglês de acordo com as necessidades do aluno, como bem pontuou o aluno-professor. Assim, a fala de Ralph leva-me a inferir que os benefícios do uso das TDIC apenas se concretizarão caso o professor tenha uma formação específica, formal, ou no curso de Letras ou em cursos de formação continuada, e essa formação se torna um desafio para qualquer professor, que precisa estar disposto a essa mudança. Nesse sentido, concordo com Kenski (2013, p. 91), ao ressaltar que os cursos de formação tecnológica para o professor passam a se tornar "uma necessidade que a nova cultura e a nova sociedade exigem"; caso contrário, aulas tradicionais tornar-se-ão cada vez mais evidentes e rotineiras nas escolas e também nas universidades e faculdades brasileiras.

Por conseguinte, no que tange à sala de aula como um ambiente de realização da prática pedagógica do professor, Ralph acredita que ultrapassa a forma física e precisa também estar relacionada à vida real do aluno. Tal fator se torna possível, em certa medida, com a utilização das tecnologias disponíveis. É o que se pode detectar nos excertos a seguir:

Transcrição 8: relato reflexivo

Ralph: A sala de aula é também o mundo do aluno, por isso o que acontece na vida dele, no mundo dele, seja visto e aconteça também na sala de aula. $\mathrm{Na}$ minha opinião, é isso que a tecnologia faz. Ela traz o mundo de fora para a sala de aula. Assim, trazer as tecnologias para a sala de aula proporciona uma certa interatividade e modernização no ensino de inglês e o professor precisa levar em consideração esses aspectos, na minha opinião.

\section{Transcrição 9: questionário final}

Ralph: A sala de aula já não tem uma medida em metros apenas, pois ela já não é apenas real; ela é também virtual.

Transcrição 10: notas de campo

Marcus: Em um seminário sobre Podcast, Ralph salienta a importância de usar essa e outras interfaces digitais na sala de aula, pois, segundo ele, a aprendizagem de 
inglês fica mais motivadora e os alunos mais descontraídos. Ele ressalta que a sala de aula precisa ser um ambiente de trocas de conhecimento e de interação entre o professor e o aluno [...].

Observa-se que Ralph traz uma percepção claramente positiva em relação à inclusão das tecnologias na sala de aula, pois a sala de aula precisa ser vista como uma extensão do mundo real do aluno, já que o aluno as utiliza frequentemente. Essa mesma opinião também foi compartilhada por Lasn anteriormente.

O aluno-professor ainda aponta que essa inclusão pode proporcionar uma aprendizagem de inglês motivadora, despertando o interesse dos alunos, possivelmente, por estarem familiarizados com interfaces digitais usadas em seus cotidianos, além de trazer modernidade e interatividade para as aulas. Na mesma perspectiva, Alonso (2017, p. 32) leva-me a perceber que "compreender, de fato, as implicações que o uso intensificado delas (das TDIC) apresenta é, sem dúvida, elemento crucial para se empreender fazeres que subsidiem, aí sim, outra maneira de organizar o fazer escolar com as TDIC" (grifo meu).

A análise do excerto número nove parece mostrar também que Ralph vê a sala de aula não apenas como um ambiente físico/real, mas também como um ambiente virtual. Assim sendo, frente ao exposto, compartilho a ideia de Moran (2013) ao defender que

com as tecnologias atuais a escola pode transformar-se em um conjunto de espaços ricos de aprendizagem significativas, presenciais e digitais, que motivem os alunos a aprender ativamente, a pesquisar o tempo todo, a serem proativos, a saber tomar iniciativas e interagir. (MORAN, 2013, p. 31).

Nessa direção, posso inferir pelas falas de Ralph que as tecnologias podem promover uma aprendizagem da língua inglesa de maneira interativa entre o professor e o aluno, em consonância com a sua realidade. Ademais, essa aprendizagem pode se expandir além das paredes das salas de aulas tradicionais.

Como pode ser observado, Ralph acredita que o professor em sua prática pedagógica com o uso das TDIC precisa:

- reclicar-se/formar-se;

- deixar de ser tradicional;

- inovar;

- ficar mais confiante para ensinar inglês;

- trazer a realidade externa do aluno para a sala de aula;

- ver também a sala de aula como um ambiente virtual e

- proporcionar interação com o aluno. 
Em suma, as ideias de Ralph relacionam as facilidades de uso das TDIC à aprendizagem do aluno da Educação Básica e à prática pedagógica do professor de inglês. Com relação ao primeiro aspecto, a contribuição volta-se para a interatividade e a modernidade, ou seja, Ralph acredita que usar as tecnologias na aprendizagem dos alunos é incluí-los tecnologicamente no contexto educacional digital, além de prepará-los para o ensino-aprendizagem de inglês com interfaces digitais que lhes são familiares em seus cotidianos.

Dessa forma, o aluno-professor acentua que as tecnologias podem trazer novidade ao ensino e despertar o interesse dos alunos em aprender a língua inglesa, pois seria uma maneira de sair de aulas de cunho tradicional - aulas em que os professores escrevem os conteúdos no quadro e os alunos copiam sem um olhar crítico, sem qualquer relação com a sua realidade, e precisam memorizar esse conteúdo para realizar algum tipo de avaliação para testar o que aprenderam em sala de aula; ou pensar em aulas expositivas em que o professor ministra o conteúdo como se estivesse conduzindo uma palestra e os alunos, comportadamente (é o que o professor espera), o escuta, sem questionamento.

Observo, portanto, que, apesar de serem reconhecidas como essenciais na educação, as TDIC ainda são pouco exploradas e usadas de maneira pedagógica em todas as suas potencialidades e possibilidades pelos professores com seus alunos. Pensar nas TDIC didaticamente é saber usá-las como interfaces protagonistas, como bem pontua o Comitê Gestor da Internet no Brasil (2016), para aprimorar o ensino e o propósito real de aprendizagem na tentativa de modificar e transformar a realidade da sala de aula tradicional. Além disso, compreendo que essas tecnologias podem capacitar o aluno a se tornar um usuário competente e crítico (COSCARELLI; KERSCH, 2016), tornando-se, assim, um agente do conhecimento (FREIRE, 1996/2004).

No que diz respeito à prática pedagógica, Ralph pontua que o professor precisa se reciclar frequentemente para ter confiança e poder inovar a sua prática de ensino-aprendizagem de inglês. A ideia subjacente nas falas de Ralph parece comungar mais com a necessidade de formação do professor, a saber, de tornarse um agente ativo, reflexivo, que sabe tomar decisões em seu contexto de ensino-aprendizagem, além de se apropriar de metodologias, de abordagens e de conhecimentos para saber agir em seu fazer pedagógico.

Essas observações me levam a pensar na relevância da formação do professor reflexivo e corroborar as ideias de Ramos e Freire (2009, p. 34) ao afirmarem que esse professor deve "conviver com incertezas e problemas concretos de sua vida profissional diária e examinar com criticidade sua prática pedagógica, seu 
contexto de trabalho e o contexto político e social em que está inserido". Assim sendo, a qualidade de suas aulas será significativa (por que o aluno está aprendendo determinado conteúdo e como esse conteúdo pode contribuir para sua formação como cidadão e para sua futura profissão; são os significados construídos para construir o conhecimento criticamente), saindo de práticas tradicionais, pois os alunos poderão se sentir motivados e desafiados a aprender a aprender.

Ralph salienta que a sala de aula pode ser uma continuação do espaço vivido pelo aluno fora da escola, o que pode proporcionar uma aprendizagem motivadora, com alunos comprometidos com o ensino de inglês. Nessa direção, comungo com as ideias de Almeida e Valente (2016, p. 32), ao pontuarem que a escola deveria ser compreendida como um espaço gerador, gestor e não apenas consumidor do conhecimento, tornando-se, assim, um ambiente de "cultura, diálogo, articulação, entre o conhecimento local e global" por meio de uso das TDIC. Em outras palavras, entendo que as TDIC podem contribuir para aulas voltadas para a realidade dos alunos e para promover a interatividade, como salienta Ralph, pois não se pode negar a importância de inclusões das tecnologias na educação. Não obstante, é válido mencionar que toda inovação precisa ser ensinada, para auxiliar o usuário a partir de suas necessidades, e o uso das TDIC em sala de aula, para uso pedagógico, não é diferente.

\section{CONSIDERAÇÕES FINAIS}

As TDIC evoluem em ritmo acelerado e transformam a maneira de pensar e de agir das pessoas na Sociedade da Informação, no lazer ou no trabalho, nas tarefas cotidianas ou na educação. É claro que, apesar de viverem na era digital, grande parte das crianças, dos jovens e dos adultos ainda não desenvolveu habilidades necessárias para atuarem em um mundo mediado pelas tecnologias. O que faz incluir, também, a área da Linguística Aplicada, que demanda práticas didáticas planejadas com a integração sistemática das TDIC no ensino-aprendizagem de inglês, como forma de criar espaços na escola brasileira (e também nas universidades e nas faculdades) para possíveis mudanças pedagógicas e tecnológicas, conscientemente.

Assim, para que a utilização das TDIC em sala de aula se transforme em uma prática corrente e organizada na educação, o papel do professor tornase fundamental, pois esse deixou de explicar, dominar conteúdos e possuir um conhecimento enciclopédico para compartilhar o conhecimento com o aluno, principalmente relacionado às tecnologias. Nessa vertente, o professor sairá do tradicional (deixará de seguir passivamente o livro didático; de ministrar aulas 
expositivas, principalmente, para crianças e jovens; de ser o detentor absoluto do conhecimento; por exemplo), e, com certeza, os alunos aprenderão inglês motivados por interfaces digitais que lhes são familiares em seus cotidianos, ou com outras interfaces introduzidas pelo professor para propósitos pedagógicos.

No contexto educacional, as TDIC precisam ser vistas como aliadas e não como obstáculos para a aprendizagem da língua inglesa. Assim sendo, o currículo deveria deixar de ser limitado apenas ao livro didático, na maioria das vezes, e possibilitar maneiras diferenciadas de apresentar o conteúdo programático por meio das potencialidades das tecnologias e das mídias digitais. Nessa direção, vejo a necessidade de revisar os currículos como forma de interligar o conteúdo da escola com o contexto real do aluno. O que pode converter as TDIC em uma potente interface para o processo de ensino-aprendizagem, tanto no contexto escolar como no acadêmico.

Em outras palavras, os dados anteriormente apresentados levam-me a deduzir que o professor deveria apresentar uma nova postura nos contextos escolar e acadêmico atuais face ao uso frequente das TDIC por seus alunos, que estão conectados o tempo todo, em qualquer lugar, a qualquer hora, fora dos muros da escola. Caso contrário, deixará seus alunos cada vez mais desmotivados e isolados no ambiente escolar, e também no acadêmico.

Após essas reflexões, a partir da pergunta da pesquisa - como o uso das TDIC se faz presente na aprendizagem dos alunos da Educação Básica e na prática pedagógica do professor na percepção de futuros professores de inglês? - sou levado a compreender que as TDIC trazem múltiplas vantagens ao serem incorporadas de maneira reflexiva e crítica à pedagogia e ao currículo na sala de aula. Não há um manual pronto e definitivo - em uma loja de departamentos ou na Internet - sobre como usar as tecnologias para fins educacionais, pois seu uso transcende o técnico e o instrumental. Faz-se necessário pensar as tecnologias como interfaces integradoras e funcionais para a formação dos alunos-professores, e por isso defendo a relevância da formação tecnológico-digital e pedagógica do professor pré-serviço de inglês nos cursos de graduação por meio de uma disciplina acadêmica curricular especifica sobre tecnologias, para torná-lo letrado digitalmente, considerando a expansão e o desenvolvimento das TDIC no mundo atual.

De forma geral, os encaminhamentos aqui mencionados procuram dar continuidade às pesquisas e contribuir com a área da Linguística Aplicada sobre os temas discriminados neste artigo, com o objetivo de aprofundar os estudos na formação tecnológico-digital e pedagógica de professores pré-serviço de inglês. Advogo a importância desses trabalhos na LA para que tais professores se sintam 
cada vez confiantes, motivados e preparados para usar as TDIC de maneira reflexiva e crítica, considerando que elas estão em constante evolução.

\section{REFERÊNCIAS}

ALMEIDA, M. E. B.; VALENTE, J. A. (2011). Tecnologias e currículo: trajetórias convergentes ou divergentes? São Paulo: Paulus.

ALMEIDA, M. E. B.; VALENTE, J. A. (2016). Políticas de tecnologia na educação brasileira: histórico, lições aprendidas e recomendações. São Paulo: Centro de Inovação para a Educação Brasileira - CIEB Estudos. Disponível em: < http://www.cieb.net.br/wpcontent/uploads/2016/12/CIEB-Estudos-4-Políticas-de-Tecnologias-na-EducaçãoBrasileira. pdf $>$ Acesso em 31 de mar. 2017.

ALMEIDA, M. E. B. et al. (2017). O currículo na cultura digital e a integração currículo e tecnologias. In: CERNY, R. Z. et al. (orgs.). Formação de Educadores na Cultura Digital. Florianópolis: UFSC/CED/NUP. Disponível em: <http://nup.ced.ufsc.br/ebooks $>$. Acesso em 27 jun. 2017.

ALONSO, K. M. (2017). Cultura digital e formação: entre um devir e realidades pungentes. In: CERNY, R. Z. et al. (orgs.). Formação de Educadores na Cultura Digital. Florianópolis: UFSC/CED/NUP. Disponível em: < http://nup.ced.ufsc.br/e-books>. Acesso em: 27 jun. 2017.

BARTON, D.; LEE, C. (2015). Linguagem online: textos e práticas digitais (Tradução Milton Camargo Mota). São Paulo: Parábola.

BATES, A. W. T. (2016). Educar na era digital: design, ensino e aprendizagem. São Paulo: Artesanato Educacional.

BERNABÉ, I. (2012). Os professores como aprendizes com as TICs. In: BARBA, C.; CAPELLA, S. (orgs.). Computadores em sala de aula: métodos e usos. Porto Alegre: Penso.

BRAGA, D. B. (2013). Ambientes digitais: reflexões teóricas e práticas. São Paulo: Cortez.

BRAGA, D. B.; VÓVIO, C. L. (2015). Uso de tecnologia e participação em letramentos digitais em contextos de desigualdade. In: BRAGA, D. B. (org.). Tecnologias digitais da informação e comunicação e participação social. São Paulo: Cortez.

BRASIL. (2017). Base Nacional Comum Curricular. Brasília: MEC/CNE. 
BRITO, G. S.; PURIFICAÇÃO, I. (2015). Educação e novas tecnologias: um (re)pensar. 2. ed. Curitiba: Editora Intersaberes.

BUCKINGHAM, D. (2010). Cultura digital, educação midiática e o lugar da escolarização. Educação \& Realidade. Porto Alegre, v. 35, n. 3, p. 37-58, set./dez.

CASTELLS, M. (2003). A galáxia da internet: reflexões sobre a internet, os negócios e a sociedade. Rio de Janeiro: Zahar.

CECCHETTINI, E. E. B. (2011). Introdução. In: VERAS, M. (org.). Inovação e métodos de ensino para nativos digitais. São Paulo: Atlas.

CELANI, M. A. A. (2010). Concepções de linguagem de professores de inglês e suas práticas em sala de aula. In: CELANI, M. A. A. (org.). Reflexões e ações (trans)formadoras no ensino-aprendizagem de inglês. Campinas: Mercado de Letras.

CELANI, M. A. A. (2016). Um desafio na Linguística Aplicada contemporânea: a construção de saberes locais. D.E.L.T.A., v. 32, n. 2, p. 543-555.

COMITÊ GESTOR DA INTERNET NO BRASIL. (2014). Pesquisa sobre o uso das tecnologias de informação e comunicação nas escolas: TIC Educação 2013. São Paulo: CGI.br.

COMITÊ GESTOR DA INTERNET NO BRASIL. (2016). Educação e tecnologias no Brasil: um estudo de caso longitudinal sobre o uso das tecnologias de informação e comunicação em 12 escolas públicas. São Paulo: CGI.br.

COSCARELLI, C. V.; KERSCH, D. F. (2016). Prefácio: pedagogia dos multiletramentos: alunos conectados? novas escolas + novos professores. In: KERSCH, D. F.; COSCARELLI, C. V.; CANI, J. B. (org.). Multiletramentos e multimodalidade: ações pedagógicas aplicadas à linguagem. Campinas: Pontes.

COSTA, F. A. (2013). O potencial transformador das TIC e a formação de professores e educadores. In: ALMEIDA, M. E. B.; DIAS, P.; SILVA, B. D. (orgs.). O cenário de inovação para a educação na sociedade digital. São Paulo: Edições Loyola.

ELEÁ, I.; DUARTE, R. (2016). Mídia-Educação: teoria e prática. In: SANTOS, E. (org.). Mídias e tecnologias na educação presencial e a distância. Rio de Janeiro: LTC.

FABRÍCIO, B. F. (2006). Linguística aplicada como espaço de "desaprendizagem": redescrições em curso. In: MOITA LOPES, L. P. (org.). Por uma Linguística Aplicada INdisciplinar. São Paulo: Parábola. 
FAVA, R. (2014). Educação 3:0 - aplicando o PDCA nas instituições de ensino. São Paulo: Saraiva.

FAVA, R. (2016). Educação para o século 21: a era do indivíduo digital. São Paulo: Saraiva.

FREIRE, P. (1996/2004). Pedagogia da autonomia: saberes necessários à prática educativa. 30 ed. São Paulo: Paz \& Terra.

FREIRE, P. (1968/2004). Pedagogia do oprimido. São Paulo: Paz \& Terra.

IANNONE, L. R.; ALMEIDA, M. E. B.; VALENTE, J. A. (2016). Pesquisa TIC Educação: da inclusão para a cultura digital. In: Pesquisa sobre o uso das tecnologias de informação $e$ comunicação nas escolas brasileiras: TIC Educação 2015. São Paulo: Comitê Gestor da Internet no Brasil.

KENSKI, V. M. (2013). Tecnologias e tempo docente. Campinas: Papirus.

LIBERALI, F. C. (2010). Formação crítica de educadores: questões fundamentais. Campinas: Pontes.

MASETTO, M. T. (2013). Mediação pedagógica e tecnologias de informação e comunicação. In: Moran, J. M.; MASETTO, M. T.; BEHRENS, M. A. Novas tecnologias e mediação pedagógica. $21^{\text {a }}$ ed. rev. e atual. Campinas: Papirus.

MOITA LOPES, L. P. (2006). Linguística Aplicada e vida contemporânea: problematização dos construtos que têm orientado a pesquisa. In: MOITA LOPES, L. P. (org.). Por uma Linguística Aplicada INdisciplinar. São Paulo: Parábola.

MORAN, J. M. (2012). A educação que desejamos: novos desafios e como chegar lá. 5a ed Campinas: Papirus.

MORAN, J. M. (2013). Ensino e aprendizagem inovadores com apoio de tecnologias. In: Moran, J. M.; MASETTO, M. T.; BEHRENS, M. A. Novas tecnologias e mediação pedagógica. $21^{\text {a }}$ ed. rev. e atual. Campinas: Papirus.

PALFREY, J.; GASSER, U. (2011). Nascidos na era digital: entendendo a primeira geração de nativos digitais. Porto Alegre: Artmed.

PÉREZ GÓMEZ, Á. I. P. (2015). Educação na era digital: a escola educativa. Porto Alegre: Penso. 
PISCHETOLA, M. (2016). Inclusão digital e educação: a nova cultura da sala de aula. Petrópolis: Vozes.

PRENSKY, M. (2001). Digital Natives, Digital Immigrants. On the Horizon. v. 9, n. 5, p. 1-5, 2001.

PRENSKY, M. (2010). Teaching digital natives: partnering for real learning. California: Corwin, a Sage Company.

PRENSKY, M. (2012). From digital natives to digital wisdom: hopeful essays for $21^{\text {st }}$ century learning. California: Corwin, a Sage Company.

RAMOS, R. C. G.; FREIRE, M. M. (2009). ESPTEC: formação de professores e multiplicadores de ensino-aprendizagem de inglês instrumental para o sistema de educação profissional de nível técnico. In: TELLES, J. A. (org.). Formação inicial e continuada de professores de línguas: dimensões e ações na pesquisa e na prática. Campinas: Pontes.

RAMOS, R. C. G. (2010). Um olhar avaliativo para o módulo fundamentos para avaliação e preparação de material didático. In: CELANI, M. A. A. (org.). Reflexões e ações (trans) formadoras no ensino-aprendizagem de inglês. Campinas: Mercado de Letras.

TAPSCOTT, D. (1999). Geração digital: a crescente e irreversível ascensão da geração net. São Paulo: Makron Books.

UNESCO. (2009). Padrões de competências em TIC para professores.

VEEN, W.; VRAKKING, B. (2009). Homo zappiens: educando na era digital. Porto Alegre: Artmed.

Recebido: 30/05/2018

Aceito: 22/10/2018 